\title{
Zergatik egiten digu alkoholak kalte?
}

\section{(Why does alcohol damage our bodies?)}

\author{
Teresa Morera-Herreras ${ }^{1 *}$, Irrintzi Fernandez-Aedo ${ }^{2}$, Cristina Miguelez ${ }^{1}$, \\ Asier Aristieta ${ }^{1}$, Luisa Ugedo ${ }^{1}$ \\ ${ }^{1}$ Farmakologia Saila. Medikuntza eta Erizaintza Fakultatea. \\ Euskal Herriko Unibertsitatea (UPV/EHU) \\ ${ }^{2}$ Erizaintza Saila I. Medikuntza eta Erizaintza Fakultatea. \\ Euskal Herriko Unibertsitatea (UPV/EHU) \\ *teresa.morera@ehu.eus
}

DOI: 10.1387/ekaia.16356

Laburpena: Gaur egun, alkohol-kontsumoa oso hedatua dago gure gizartean. Nahiz eta gizartearen aldetik oso onartua egon, iradoki izan da batetik efektu euforikoak eragiten dituela, eta bestetik asaldura fisiko zein psikiko kaltegarriak eragin diezazkiokeela organismoari. Alkoholaren zinetika nahiko aldakorra izan daiteke eta horrek nabarmen baldintzatzen ditu organismoan sortzen diren eragin akutuak. Bestalde, alkoholaren luzaroko kontsumoak ere efektu kaltegarriak ditu, esate baterako, menpekotasuna. Ondorioz, gizakiak alkoholdun edariak hartzeko behar handia sumatzen du. Horrekin lotuta, alkoholikoak tolerantzia garatuko du, eta gero eta alkohol kantitate handiagoak beharko ditu. Artikulu honetan, berrikusi egingo dira gorputzeko alkohol kontzentrazio handiagoak baldintzatzen dituzten prozesu zinetiko garrantzitsuenak, baita alkoholak eragindako efektu akutuak zein kronikoak ere.

Hitz gakoak: Etanola, menpekotasuna, abstinentzia-sindromea, tolerantzia.

Abstract: Alcohol consumption has widespread use and acceptance in today's society. Besides the euphoric effect, alcohol can also produce unpleasant psychological and physical side effects. The acute effects of alcohol depend on its kinetics which varies among the individuals. On the other hand, prolonged use can also produce severe unwanted effects, such as dependence. As a consequence, the person will have an urgent need to drink alcohol. At the same time, the alcoholic will develop tolerance and therefore higher amounts of alcohol will be required for obtaining the same effects. In this article, we will review the kinetic processes that have a higher impact in alcohol plasmatic concentrations. We will also analyze the acute and chronic effects induced by alcoholic beverages.

Keywords: Ethanol, dependence, abstinence syndrome, tolerance. 
Teresa Morera-Herreras, Irrintzi Fernandez-Aedo, Cristina Miguelez, Asier Aristieta, Luisa Ugedo

\section{SARRERA}

Gizakiak betidanik lortu ditu edari alkoholdunak barazkien hartzidurari esker. Ekintza aspergarrietatik edo neke-eragileetatik ihes egiteko erabiltzen zen kultura gehienetan. Era berean, mina arintzeko zein ur eskasiari aurre egiteko erabiltzen zen. Alkohol hitzak arabiar hizkuntzan du jatorria (alkohl), hauts hitzean alegia. Gizarteak onartua dauka alkoholkontsumoa eta alkohola erraz lor daiteke, baina hala ere, ez da ahaztu behar drogatzat hartzen duela Munduko Osasun Erakundeak. Izan ere, nerbio-sistema zentralean depresioa eragiten du, tolerantzia eta dependentziarekin lotuta.

Alkoholak eragiten dituen arazoak ekiditea ez da erraza, herrialde industrializatuetan legearen barruan eros daitekeen produktua baita. Munduko beste herrialdeekin konparatuta, kontuan hartzen badugu alkohol kontsumoa biztanleko, Espainiar estatua hemezortzigarren postuan kokatuta dago $[1,2]$. Beraz, badirudi zaila dela alkoholak sortzen dituen kalteak ekiditea denbora laburrean, behintzat.

Alkoholaren gehiegizko kontsumoak gizarte arazoak zein osasun publikoko arazoak dakartza. Alde batetik, auto-istripu edota lan-istripuak ugariagoak gertatzen dira alkohola kontsumitzen denean. Hori ikus daiteke auto-istripuetan inplikaturik dauden gidarien odol-analisiak aztertzen direnean. Bestetik, gaixotasun ugari daude gehiegizko alkohol-kontsumoarekin lotuta, eta horrek diru-galera handiak dakarzkio gizarteari [3].

\section{ZER DA ALKOHOLA?}

Alkoholen taldearen barruan etanola edo alkohol etilikoa (96 graduko alkohola) dira alkoholdun edarietan gehien agertzen dena. Etanola, mahatszukua edo sagar-zukua bezalako edari azukretuetan sortzen da hartzidura anaerobikoaren (hau da, oxigenorik gabeko hartziduraren) ondorio modura. Alkoholdun edari batek duen alkohol kantitatea gramotan kalkula daiteke ondorengo formularen bidez:

$$
\begin{aligned}
& \text { Irentsitako alkohol kantitatea }(\mathrm{g})=\frac{\text { Irentsitako kantitatea }(\mathrm{ml}) \times \text { gradu zenbakia } \times 0,8^{*}}{100} \\
& * \text { etanolaren dentsitatea }(\mathrm{g} / \mathrm{ml})
\end{aligned}
$$

Horrela, $12^{\circ}$-ko $100 \mathrm{ml}$ ardo edanez gero, 9.6 gramo alkohol puru irentsiko genituzke. 1.taulan ikus daitezke Euskal Autonomia Erkidegoan gehien kontsumitzen diren alkoholdun edarien zerrenda eta haien alkohol kopurua. 
1. taula. Edarietako alkohol puruaren kantitatea.

\begin{tabular}{lccc}
\hline \multicolumn{1}{c}{ Edaria } & $\begin{array}{c}\text { Gradu } \\
\text { alkoholikoa }\end{array}$ & $\begin{array}{c}\text { Bolumena } \\
(\mathrm{ml})\end{array}$ & $\begin{array}{c}\text { Alkohol purua } \\
(\mathrm{g})\end{array}$ \\
\hline Garadardo-potoa & $5^{\circ}$ & 333 & 13.3 \\
Kaña & $5^{\circ}$ & 200 & 8.0 \\
Baso bat ardo & $12^{\circ}$ & 100 & 9.6 \\
Botila bat ardo & $12^{\circ}$ & 750 & 72.0 \\
Kopa bat Portoko ardo & $17^{\circ}$ & 70 & 9.5 \\
Kopa bat likore & $23^{\circ}$ & 45 & 8.3 \\
Kopa bat brandy, ron edo gin & $38^{\circ}$ & 45 & 13.6 \\
Konbinatuak & $38^{\circ}$ & 50 & 15.2 \\
\hline
\end{tabular}

Gauzak horrela, esan beharra dago alkoholak denbora epe desberdinak behar dituela denbora bakoitzarengan arazoak eragiteko. Hau dela eta, ezinezkoa da osasunari orokorki kalte egiten dion alkohol kantitatea zehaztea. Orientazio gisa, «Health Education Council» Erakundeak (Osasunerako Hezkuntza Erakundeak) proposatutako kantitateak alegia gizonentzako 210 gramo asteko, eta emakumezko 140 gramo asteko.

\section{ALKOHOLAREN XURGAPENA, BANAKETA ETA IRAIZKETA. ALKOHOLAREN ZINETIKA}

Etanola, batez ere, aho bidez hartzen da eta horren ondorioz, xurgapena eta banaketa prozesua zinetikoak jasan behar izaten ditu. Horrela, odolera iristen da eta odolaren bidez azkenean kaltetuak gertatzen diren ehunetara. Era berean gure organismoak metabolismoa eta iraizketa direlako prozesu zinetikoak jartzen ditu abian $[4,5]$.

\subsection{Xurgapena}

Alkohola edan eta berehala, xurgapena hasten da bereziki heste meharrean. Minutu gutxiren buruan, odolera heltzen da eta handik ehun guztietara banatuta, bere eraginik handiena 30 minututan lortzen du.

Hainbat egoerak baldintzatzen dute alkoholaren xurgapena. Jatean, eta batez ere koipedun jana, urdailaren hustuketa atzeratu egiten da eta, horrekin batera, alkoholaren xurgapena ere. Edarien ezaugarriek ere, eragiten diote alkoholaren xurgapenari. Esate baterako, karbono dioxidoaren bidez gasifikatutako edariek (xanpainak, esate baterako) azkartu egiten dute urdailaren hustuketa eta xurgapena oso azkar gertatzen da heste meharrean. Alkohola edaten dugun bitartean tabakoa erretzeak odoleko alkohol kontzentrazioa gutxitu egiten du, agian, urdailaren hustuketa moteltzen due- 
Teresa Morera-Herreras, Irrintzi Fernandez-Aedo, Cristina Miguelez, Asier Aristieta, Luisa Ugedo

lako eta, ondorioz, alkoholaren xurgapena heste meharrean gutxitzen delako ziur aski.

\subsection{Banaketa}

Behin alkohola odolera iritsita, ehun eta gorputzeko likidoetara abiatuko da, eta haurdun dauden emakumeen plazentara ere iristen da. Nahiz eta alkohola molekula anfipatikoa izan, uretan lipidoetan baino hobeto disolbatzen da, erlazioa gutxi gorabehera 30/1ekoa izanik. Ondorioz, uretan aberatsak diren ehunek alkoholaren kantitate handiagoa jasoko dute. Muskulu-ehunak urez osatuta daude \%80an, baina gantz-ehunak aldiz \%20koa dute uraren proportzioa, eta beraz, muskulu-ehunak alkohol gehiago jasotzen du.

Etanolak lipidoetan baino hobeto disolbatzeko duen ezaugarri horrek, banaketa desberdinak eragiten ditu gizakietan, bakoitzak duen gantz kantitatearen arabera. Hala gertatzen da pisua eta irentsitako alkoholaren kantitatea berdinak izanda ere. Beraz, emakumeen eta gizonen arteko desberdintasun biologikoek gantz kantitatean eragiten dituzten desberdintasunak direla eta, pentsatzekoa da alkohol-banaketa desberdinak gertatuko direla sexuaren arabera (0.7 1/kg gizonengan eta $0.61 / \mathrm{kg}$ emakumeengan). Horrela ba, emakumeek pisu txikiagoa dute, eta ondorioz, etanol maila handiagoa dute odolean, hau da, alkoholemia maila handiagoa pairatuko dute, alkohol kantitate bera edanda ere. Era berean, adinean aurrera joan ahala, gantz kantitatea gehitzen doa, eta ondorioz etanolaren kontzentrazio plasmatikoa ere handitzen doa.

\subsection{Iraizketa}

Alkoholaren metabolismoaren \%95a gibelean gertatzen da oxidazio prozesuaren bidez. Horrela, etanola azetaldehido bihurtzen da alkohol deshidrogenasa entzimari esker. Geroago, aldehido deshidrogenasa entzimak azetaldehidoa metabolizatuz, azetatoa sortzen du. Azkenik, azetatoa, erraz kanporatzeko, karbono dioxido eta ur bihurtzen da.

Alkoholaren \%5ak, ez du prozesu hau jasaten, eta gernu, arnas eta gorozkien bitartez iraizten da. Hau garrantzi handikoa da toxikologiaren ikuspegitik. Izan ere, alkohol maila neurtzeko balio du horrek (alkoholemia-probaren bidez). Hori dela eta, arnas bidez kanporatzen den alkohola erabiltzen da alkoholemia-kontrolak egiteko.

Alkoholaren iraizketaren abiaduran ere, gizakien arteko ezberdintasunak badaude. Ezberdintasun hauek txikiak dira eta onartzen da, orokorrean, iraizketaren abiadura 10-20 mg-koa dela $100 \mathrm{ml}$ odoleko eta orduko. Iraizketaren abiaduran, ez dute eraginik ez sexuak, ez eta adinak ere. Iradoki izan da, ordea, alkohola edaten den maiztasuna metabolismoa eta iraizketa handitu egiten dituela. 
Zergatik egiten digu alkoholak kalte?

\subsection{Alkoholaren kurba odolean}

Prozesu hauek guztiak aurrera doazen heinean, alkoholaren maila aldatzen doa, alkoholaren kurban ikus daitekeen bezala (1. irudia). Odolean dugun alkoholaren kontzentrazioa aldatzen doa, orduak aurrera joan ahala, 3 kopa ardo edan ostean. Alkohola edan eta 5 minutura odolean agertzen da. Denbora igaro ahala, kontzentrazioa handitzen doa eta iraizketa hasten denean alkoholaren maila jaisten da.

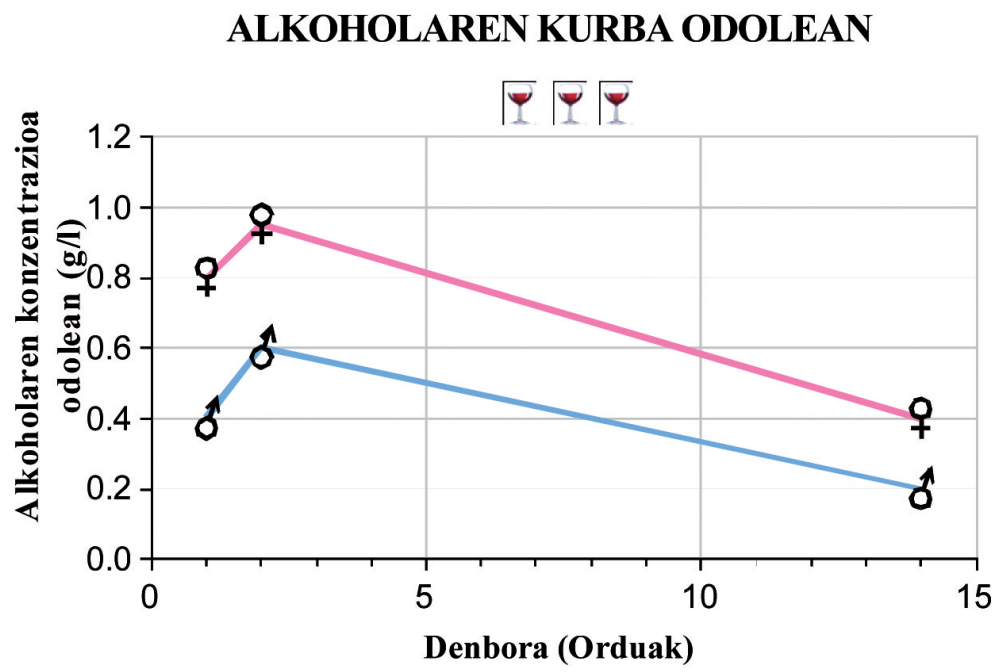

1. irudia. Grafiko honek adierazten du 3 kopa ardo hartu ondorengo alkoholaren kontzentrazio plasmatikoa odolean. Kontzentrazio plasmatiko maximoa ordu bat igaro eta gero gertatzen da. Denbora tarte horretan xurgatzen da hartutako alkoholik gehiena (kurbaren goranzko zatia). Hurrengo orduetan alkoholaren banaketa eta iraizketa gertatzen dira da (kurbaren beheranzko zatia).

\section{INTOXIKAZIO AKUTUA}

Alkohol kantitate handia hartzearen ondorioz sortzen da, larrialdi-zerbitzuetan ikusten den intoxikazio ohikoena [3]. Sintoma klinikoak nerbiosistema zentralaren afekzioaren ondorioak dira, eta aurretiaz esan bezala, odoleko alkoholaren kontzentrazioaren menpe daude. Ohituta ez dauden gizakiengan, etanolaren eragin neurotoxikoa $50 \mathrm{mg} / \mathrm{dl}-\mathrm{ko}$ alkohol tasarekin igartzen hasten da. Aldiz, tolerantzia dutenek ohiko portaera erakusten dute odoleko alkohol maila handiagoa hartuta ere $[3,7,8]$.

Alkoholak eragindako intoxikazio akutuaren koadroa, gizartearen aurkako jokabideko egoera gisa defini daiteke, ezaugarri hauek nabarmendu daitezkeelarik: oldarkortasuna, sexu-jokabide ezegokia, gogo-aldartearen 
Teresa Morera-Herreras, Irrintzi Fernandez-Aedo, Cristina Miguelez, Asier Aristieta, Luisa Ugedo

aldaketa zakarrak eta gizarte eta lan-jokabide ezegokiak, besteak beste. Alkoholak oroimen-asaldurak eragiten ditu, eta kantitate handia edaten denean, denboraldi jakin bateko oroimen-galerak agertzen dira. Kasu horietan gehiegi edan duen gizakiak ez du egindakoa gogoratzen. Alkohol-intoxikazioa jasan eta hurrengo egunean, edaleak «bestondo» bezala ezagutzen den ondoeza paira dezake. Horrez gain, edaleak alhadura eta erru sentimenduak paira ditzake. Intoxikazio ondoko sintomatologia oso anitza da, eta hartutako alkoholaren kantitatearen eta edalearen sentikortasunaren araberakoa gertatzen da hori. Oso ohikoak dira hainbat sintoma: buruko mina, egarria, bertigoa, sabeleko ondoezak, goragaleak, insomnioa, eskuetako dardara eta gibelaren funtzioaren asaldurak. Normalean, sintoma hauek pare bat egunean desagertzen dira $[3,7]$.

\section{ALKOHOLEKIKO TOLERANTZIA ETA MENPEKOTASUNA}

Alkoholaren luzaroko kontsumoaren ondoren, gorputzak zenbait moldaketa garatzen ditu [7, 9]. Gizaki batek alkohola denbora luzez edaten duenean, zenbait prozesu fisiologiko aldatu egiten dira gradualki. Mekanismoa ez da oraindik zehatz ezagutzen, baina ikerketa askok egiaztatu dute sistema GABAergiko eta glutamatergikoak aldaketa larriak pairatzen dituztela alkohol-kontsumoaren ondorioz. Hain zuzen ere, burmuineko zenbait nukleotan, GABA-hartzaileen kopurua murriztu egiten da eta aitzitik, NMDA hartzaile glutamatergikoen zenbakia areagotu egiten da [10]. Egoera honetan, organismoak normaltasunez funtziona dezake gutxi gorabehera, nahiz eta alkoholaren eraginak nabaritu. Hala ere, aldaketa hauek direla eta, burutzearen organismoak alkohola dagoenean bakarrik funtziona dezake normaltasunez. Gizaki bat alkoholaren menpeko bilakatu denean eta alkohola eskuragarri ez duenean, abstinentzia-sintoma akutuak pairatuko ditu.

Etanola behin baino gehiagotan emanda, efektuen intentsitateak behera egiten du, hau da, tolerantzia garatzen da. Tolerantzia, beraz, efektu baten intentsitateak duen ahalmenaren potentziaren galera bezala defini daiteke. Normalean, efektuaren intentsitatea berreskura daiteke dosia handituz. Tolerantzia hiru mailatan gertatzen da:

1. 2 edo 3 astean zehar alkohol kantitate handiak edan ostean, gibelak alkohola metabolizatzeko ahalmen handiagoa garatzen du (alkoholedaleak edaten ez duenak baino \%30 ahalmen handiagoa izan dezake).

2. Organismoa odoleko alkohol maila handiekin egoera egokian lan egitera ohitzen da, ikasitako konpentsazio mekanismoak garatzen dituelako (esate baterako, zuzen ibiltzen ikasten da ikastea).

3. Organismoan aldaketak gertatzen dira alkoholaren eragin jarraituari egokitzeko. 
Alkoholaren eraginpean behin eta berriz egon ostean gertatzen diren aldaketen ondorioz, alkoholarekiko menpekotasuna garatzen da, eta alkohola edan behar da ondoezik ez sentitzeko. Edateari utzita, alkoholarekiko abstinentzia-sindromea agertuko da, eta edatearen gaineko kontrola galdu egingo da. Horrek, alkoholarekiko menpekotasuna duten gizakiek gogorik ez dutenean ere edatea eragiten du. Alkohol-kontsumitzaile handiek goizetan edaten dute odoleko alkoholaren kontzentrazioak berriz igotzeko, loaldian behera egiten baitute. Gainera, esnatzen badira alkoholdun edaria hartzen dute gutxitutako alkoholaren kontzentrazioak eragiten dien egonezina ekiditeko. Hau gertatzen denean esan dezakegu, oro har, gizakia drogazale bihurtu dela, eta alkohol kontsumitzaileentzat bereziki, alkoholiko hitza erabiliko dugu.

\section{ALKOHOLAREKIKO ABSTINENTZIAREN SINDROMEA}

Alkoholaren ahorakina bertan behera uzteak abstinentzia-sindrome kaltegarria eragiten du [11]. Sindrome honen sintomak alkoholaren efektuen errebotearenak dira (2. taula). Alkohol-kontsumoaren iraupenak, alkohol kantitateak eta etanolaren metabolismo-abiadurak baldintzatu egiten dute abstinentzia-sindromearen intentsitatea. Neurrizko kontsumoa izanez gero, hurrengo 6-8 orduetan sintoma arinak agertuko dira, esate baterako goizeko

2. taula. Alkoholaren abstinentzia-sindromearen sintomatologia.

\begin{tabular}{|c|c|}
\hline \multicolumn{2}{|c|}{ Alkoholaren abstinentzia-sindromea } \\
\hline \multicolumn{2}{|l|}{ Edateko gogo handia } \\
\hline \multicolumn{2}{|l|}{ Dardara } \\
\hline \multicolumn{2}{|l|}{ Suminkortasuna } \\
\hline \multicolumn{2}{|l|}{ Lo-aldaketak } \\
\hline \multicolumn{2}{|l|}{ Takikardia } \\
\hline \multicolumn{2}{|l|}{ Hipertentsioa } \\
\hline \multicolumn{2}{|l|}{ Izerdia } \\
\hline \multicolumn{2}{|l|}{ Oharmen-deformazioa } \\
\hline \multicolumn{2}{|l|}{ Konbultsioak } \\
\hline \multicolumn{2}{|c|}{ Delirium tremens: Asaldura } \\
\hline & Nahastea \\
\hline & Ikusmen-haluzinazioak \\
\hline & Sukarra, izerdi oparoa \\
\hline & Takikardia \\
\hline & Goragaleak, beherakoa \\
\hline
\end{tabular}


Teresa Morera-Herreras, Irrintzi Fernandez-Aedo, Cristina Miguelez, Asier Aristieta, Luisa Ugedo

dardara, loezina, suminkortasuna, goragale eta okadak, anorexia, takikardia edo hipertentsio arinak. Sintoma horiek 3-5 egun iraun dezakete. Zenbat eta alkohol gehiago kontsumitu, orduan eta sintoma larriagoak ager daitezke. Alkohola edateari utzi eta hurrengo egunetan gerta daiteke konbultsioak eta haluzinazio alkoholikoak pairatzea. Une horretan, pazienteari tratamendu egokia agindu ezean, gerta daiteke delirium tremens jasan behar izatea, hau da, egoera patologikoa okerragotzea. Delirium tremens ondorio larria denez, ospitalean tratatu beharreko gaitza da. Sarritan, pazienteak gehiegizko urduritasuna sentitzen du, baita nahastea, haluzinazioak, sukarra, midriasia edota hipertentsioa. Beraz, tratamendu egokia eduki ezean, pazienteen \%15a hil egiten da.

\section{ALKOHOLISMOA}

Munduko Osasun Erakundeak emandako definizioaren arabera, eguneko 70 gramo alkohol baino gehiago hartzen duten gizonak alkoholikotzat har daitezke (14 kopa ardo edo 4 kopa whisky, adibidez). Emakumeek, gaixoak direla esateko, 50 gramo alkohol eguneko baino gehiago edan behar dute (10 kopa ardo edo 3 kopa whisky). Alkoholaren kontsumoaren kontrola galdu duenari alkoholikoa deitzen zaio. Osasunerako kaltegarria da, baina lan eta senitarte-esparruetan ere arazoak sortzen ditu. Alkohol-arazoak dituen gizakia alkoholaren menpean biziko da. Ez dago alkoholismoaren jatorri eta jarraitasuna azaltzen duen zergati bakarra; izan ere, badirudi gaixotasun honetan parte hartzen dutela gene, bizarte eta adina bezalako fisiologia-faktoreek [3].

Alkoholikoak alkoholdun edari ugari kontsumitzen ditu egunero eta, horren ondorioz, menpekotasuna eta tolerantzia garatzen ditu. Menpekotasuna lehenengo 5 urteetan sortzen da eta pixkanaka indartuz doa hurrengo 25 urteetan zehar. Hasieran, tolerantzia agertzen da eta berez, alkohola badirudi gero eta hobeto jasaten dela. Geroago, oroimen-alterazioak eta kontsumo-kontrolaren galera sortzen dira. Alkoholismoa sendo finkatuta dagoenean, alkoholaren kontsumoa da alkoholikoaren lehentasunik garrantzitsuena. Horrela, gaixoa ez da higienez, lanpostuaz edo harreman pertsonalez batere arduratzen. Gehiegizko edatea kaltegarria dela jakin arren gaixoak ezin dio edateari utzi eta ondorioz asaldura psikiatrikoak sarritan agertzen dira. Honez gain, oso ohikoa izaten da berriz edaten hastea.

Gaur egun alkoholismoaren intzidentzia areagotuz doa. Estatistiken arabera, Europan zehar helduen \%7a alkoholikoa da, eta horrek diru eta gizarte-arazo larriak sortzen ditu. Osasun Mentalaren Elkarte Amerikarrak dioenez, pertsona bat alkoholikoa den esateko, hurrengo irizpideetatik behintzat 3 bete behar ditu [7]:

- Alkoholekiko tolerantzia jasatea.

- Alkohola kontsumitu ezean abstinentzia-sindromea pairatzea.

- Abstinentzia-sindromearen sintomak ekiditeko alkohola kontsumitzea. 
- Gehiegizko alkohola edatea.

- Saiatuta ere alkohol gutxiago edateko ezintasuna izatea.

- Denbora luzea ematea alkohol bila.

- Alkoholaren erruz bestelako jarduerei uko egitea.

- Alkoholak eragiten dituen ondorio kaltegarriak ezagutu arren, edaten jarraitzea.

Abstinentzia-sindromea arintzea da alkoholismoaren tratamenduan ematen den lehen urratsa. Behin sintomak desagertuta, gomendatzen da asaldura psikologiko eta fisiologikoak sendatu arte jarraitzea tratamenduan. Tratamenduak bi helburu ditu, alkoholarekin lotutako sintomak ezabatzea eta gaixoari alkohola edatea saihestea. Zoritxarrez, bi helburu hauek ez dira beti lortzen eta desintoxikazioak arrakasta izan arren, gaixoa berriro alkohola edaten hasten da askotan. Bestalde, etanolak eragindako arazo kronikoak ere tratatzeko beharra dago gaixo hauengan [3].

\section{LUZAROKO ALKOHOL-KONTSUMOAREKIN LOTUTAKO ASALDURAK}

Medikuntzaren ikuspuntutik alkohola asaldura somatikoak zein psikiatrikoak eragiteko ahalmena dauka (3. Taula). Ager daitezkeen gaixotasunak, kasu askotan, zenbait organotan alkoholak eragindako etengabeko efektuaren ondorioa dira. Esanguratsuenen artean hurrengoak daude [12]:

\subsection{Gibelean}

Alkoholak kalte larriak eragin ditzake gibelean, besteak beste, zirrosia. Patologia honetan, hepatozitoen ordez, hau da, gibel-zelula funtzionalen ordez, ehun haritsua agertzen da (ehun ez funtzionala). Ondorioz, alkohola edaten duenak gibel-gutxiegitasuna pairatuko du. Egoera hau oso larria da eta oso zaila tratatzeko. Etanolak eragindako beste gaixotasun ohikoa hepatitis alkoholikoa da. Gaixotasun honen larritasuna aldatzen doa: hasieran sintomarik gabekoa da baina denbora pasa ahala, kasurik larrienetan gibelzelulen gutxiegitasun larri bilakatzen da alkohol-kontsumoarekin batera.

\subsection{Pankrean}

Alkoholak pankreatitis akutua eragin dezake (pankrearen hantura akutua). Kasurik larrienetan bizitza kolokan jartzen da.

\subsection{Nerbio-sistema periferikoa}

Alkohol-kontsumo patologikoak, neuropatia alkoholiko izeneko gaixotasuna sor dezake. Hortaz, sistema periferikoaren kalteak sortzen dira, esate baterako karranpak, ibilketaren alterazioak. 
Teresa Morera-Herreras, Irrintzi Fernandez-Aedo, Cristina Miguelez, Asier Aristieta, Luisa Ugedo

\subsection{Digestio-aparatuan}

Hain zuzen ere, ohiko eta gehiegizko kontsumoak gastritis kronikoa eragiten du urdailean. Horren ondorioz, mina eta mukosa gastrikoaren hantura erakusten dira eta bitaminen xurgapen txarra sorrarazten du (batez ere, B taldekoarenak). Aurreko guztiak desnutrizioa sortzen du. Askotan, halako arazoa atzematen da alkoholiko kronikoengan.

3. taula. Alkoholaren luzaroko kontsumoarekin lotutako asaldurak.

\begin{tabular}{|c|c|}
\hline Hunkitutako Organo/sistema & Asaldura \\
\hline Digestio aparatua & $\begin{array}{c}\text { Gastritisa edo esofagitisa } \\
\text { Elikagaien xurgapen murriztuta } \\
\text { Kartzinoma gastrikoa edo esofagikoa } \\
\text { Koloneko minbizia }\end{array}$ \\
\hline Pankrea eta gibela & $\begin{array}{l}\text { Pankreatitisa } \\
\text { Zirrosia } \\
\text { Hepatitis alkoholikoa } \\
\text { Kartzinoma }\end{array}$ \\
\hline Aparatu kardiobaskularra & $\begin{array}{l}\text { Hipertentsioa } \\
\text { Bihotzeko arritmiak } \\
\text { Koronariopatiak }\end{array}$ \\
\hline Odola & $\begin{array}{c}\text { Anemia } \\
\text { Infekzioaren kontrako erantzun ahula }\end{array}$ \\
\hline Muskuluak eta hezurrak & $\begin{array}{l}\text { Muskulu-zuntzen alterazioak } \\
\text { Osteoporosia }\end{array}$ \\
\hline Arnas aparatua & $\begin{array}{l}\text { Loaren apnea } \\
\text { Pneumonia } \\
\text { Birikako minbizia }\end{array}$ \\
\hline Endokrinoa eta metabolismoa & $\begin{array}{c}\text { Diabetesa } \\
\text { Hezueria } \\
\text { Nutrizio-hutsuneak }\end{array}$ \\
\hline Ugaltze-aparatua & $\begin{array}{c}\text { Barrabilen funtzioaren murrizketa } \\
\text { Obulutegi-funtzioaren murrizketa } \\
\text { Bularreko minbizia }\end{array}$ \\
\hline Nerbio-sistema & $\begin{array}{c}\text { Depresioa eta suizidio-saioak } \\
\text { Dementzia } \\
\text { Antsietatea } \\
\text { Epilepsia } \\
\text { Iktusa }\end{array}$ \\
\hline
\end{tabular}


Zergatik egiten digu alkoholak kalte?

\section{ALKOHOLA ETA HAURDUNALDIA}

Lehen esan bezala, alkoholak oso erraz zeharkatzen ditu mintzak. Horrela, muga plazentalioa zeharkatzen du eta feturaino ailegatuta, bere garapenari eragingo dio. Haurdunaldian zeharreko alkohol-kontsumo kronikoak fetu-garapenean aldaketak eragiten ditu eta umetoki barneko hazkuntza atzeratu egiten du. Horren ondorioz, jaioberriengan aldaketak agerian geratuko dira, esate baterako: pisu baxua, sortzetiko anomaliak (ahoan eta traktu genitourinarioan, suminkortasuna, adimen-atzerapena) eta, kasu larrienetan, sindrome alkoholiko fetala (malformazioa: aurpegi zapala, goiko ezpain estua, begi eta sudur bereziak, ikasteko zailtasuna eta adimen-atzeratasuna). Sindrome alkoholiko fetalaren frekuentzia 1-3/1.000 jaiotzekoa dela estimatzen da (Downen sindromearen antzera). Ikerketa batzuen arabera, haurdun dauden emakumeen \%24a arrisku-kontsumitzailea da [13].

\section{BADU ALKOHOLAK EFEKTU ONURAGARRIRIK?}

Alkoholaren kontsumoak efektu onuragarriak dituelako ideia oso hedatua dago gure artean. Hain zuzen ere, munduan zehar egindako ikerketa batzuek, iradokitzen dute alkohol kantitate txikiak edo moderatuak kontsumitzeak hilkortasun tasa murrizten duela (batez ere, ardoaren kontsumoan). Hala gertatzen da bereziki gaixotasun kardiobaskularretan [14]. Munduko Osasun Erakundeak, ordea, erabat ukatzen du edari alkoholikoen edozein efektu terapeutiko.

\section{BIBLIOGRAFIA}

[1] SASSI, F. 2015. Tackling Harmful Alcohol Use: Economics and Public Health Policy. OECD Publishing, Paris.

[2] Observatorio del Plan Nacional Sobre Drogas. http://www.pnsd.msssi.gob. es/fr/profesionales/sistemasInformacion/home.htm

[3] GUAL, A. 2012. «Monografía alcohol». Adicciones, 1(1), 1-451

[4] FLORES, J., ARMIJO, J.A. eta MEDIAVILLA, A. 2013. Farmacología Humana. 6. ${ }^{\text {a }}$ ed, Masson, España.

[5] LAURENCE, B. 2012. Goodman \& Gilman. Bases farmacológicas de la terapéutica. 12 . $^{\mathrm{a}}$ ed, McGraw-Hill Interamericana, E.E.U.U.

[6] MICHALAK, A. eta BIALA, G. 2016. «Alcohol dependence neurobiology and treatment». Acta Poloniae Pharmaceutica, 73(1): 3-12.

[7] LORENZO, P., LADERO, J.M., LEZA, J.C. eta LIZASOAIN, I. 2006. Drogodependencias, (Farmacología. Patología. Psicología. Legislación). 3. a ed. Panamericana, Argentina. 
Teresa Morera-Herreras, Irrintzi Fernandez-Aedo, Cristina Miguelez, Asier Aristieta, Luisa Ugedo

[8] URSO, T., GAVALER, J.S. eta VAN THIEL, D.H. 1981. «Blood ethanol levels in sober alcohol users seen in an emergency room». Life Sciences, 28(9):1053-6.

[9] PEREZ-RIAL, S., ORTIZ, S. eta MANZANARES, J. 2003. «Neurobiología de la dependencia alcohólica». Trastornos adictivos, 5(1):4-12.

[10] COSTIN, B.N. and MILES, M.F. 2014. «Molecular and neurologic responses to chronic alcohol use». Handbook of clinical neurology, 25:157171.

[11] BRUST, J.C. 2014. «Acute withdrawal: diagnosis and treatment». Handbook of clinical neurology, 125:123-131.

[12] FEDERICO, A., COTTICELLI, G., FESTI, D., SCHIUMERINI, R., ADDOLORATO, G., FERRULLI, A., MERLI, M., LUCIDI, C., MILANI, S., PANELLA, C., DOMENICO, M., VANTINI, I., BENINI, L., UBALDI, E., ROMANO, M. eta LOGUERCIO, C. 2015. «The effects of alcohol on gastrointestinal tract, liver and pancreas: evidence-based suggestions for clinical management». European Review for Medical and Pharmacological Sciences, 19(10): 1922-1940.

[13] CAPUTO, C., WOOD, E. eta JABBOUR, L. 2016. «Impact of fetal alcohol exposure on body systems: A systematic review». Birth Defects Research: Part C Embryo Today Reviews, 108(2):174-180.

[14] ARTERO, A., ARTERO, A., TARIN, J.J. eta CANO, A. 2015. «The impact of moderate wine consumption on health». Maturitas, 80(1):3-13. 